\title{
Types of 23S Ribosomal RNA Point Mutations and Therapeutic Outcomes for Helicobacter pylori
}

\author{
Sang Yoon Kim¹, Jae Myung Park ${ }^{1,2}$, Chul-Hyun Lim³ ${ }^{3}$,Hye Ah Lee ${ }^{4}$, Ga-Yeong Shin ${ }^{1}$, Younghee Choe ${ }^{1}$, Yu Kyung \\ $\mathrm{Cho}^{1}$, and Myung-Gyu Choi ${ }^{1,2}$ \\ ${ }^{1}$ Division of Gastroenterology, Department of Internal Medicine, Seoul St. Mary's Hospital, College of Medicine, The Catholic \\ University of Korea, ${ }^{2}$ Catholic Photomedicine Research Institute, College of Medicine, The Catholic University of Korea, ${ }^{3}$ Division of \\ Gastroenterology, Department of Internal Medicine, Eunpyeong St. Mary's Hospital, College of Medicine, The Catholic University of \\ Korea, and ${ }^{4}$ Clinical Trial Center, Ewha Womans University Mokdong Hospital, Seoul, Korea
}

See editorial on page 487 .

\section{Article Info}

Received July 20, 2020

Revised September 21, 2020

Accepted September 21, 2020

Published online December 31, 2020

\section{Corresponding Author}

Jae Myung Park

ORCID https://orcid.org/0000-0002-1534-7467

E-mail parkjerry@catholic.ac.kr

\section{Chul-Hyun Lim}

ORCID https://orcid.org/0000-0002-8347-8979

E-mail diluck@catholic.ac.kr
Background/Aims: Point mutations in the 23S ribosomal RNA gene have been associated with Helicobacter pylori clarithromycin resistance. This study aimed to detect the prevalence of these point mutations and to investigate the role of different point mutations in the success of eradication therapy.

Methods: We retrospectively investigated a total of 464 consecutive patients who underwent an endoscopic examination and dual-priming oligonucleotide-based multiplex polymerase chain reaction for $\mathrm{H}$. pylori between June 2014 and October 2019. For 289 patients with negative point mutations, standard triple therapy was used in 287 patients, and the bismuth-quadruple regimen was used in two patients. For 175 patients with positive point mutations (A2142G, A2143G, and both mutations), standard triple and bismuth-quadruple therapies were used in 37 patients and 138 patients, respectively.

Results: The eradication rates of standard triple and bismuth-quadruple therapies showed no significant difference in mutation-negative patients or those with the A2142G point mutation. However, the eradication rate with bismuth-quadruple therapy was significantly higher than that with standard triple therapy in the group with the A2143G mutation or with the double mutation. The eradication rates for standard triple and bismuth-quadruple therapies, respectively, were $25.8 \%$ and $92.1 \%$ in the per-protocol group $(p<0.001)$ and $24.2 \%$ and $85.2 \%$ in the intention-totreat analysis $(p<0.001)$.

Conclusions: The A2143G point mutation is the most prevalent cause of clarithromycin resistance. Bismuth-quadruple therapy is superior to standard triple therapy in patients with the A2143G or double point mutation. (Gut Liver 2021;15:528-536)

Key Words: Helicobacter pylori; Therapy; Clarithromycin; Drug resistance; Point mutation

\section{INTRODUCTION}

Helicobacter pylori infection is closely associated with peptic ulcer disease, gastric mucosa-associated lymphoid tissue lymphoma, and gastric adenocarcinoma. ${ }^{1}$ Eradication of the infection markedly reduces the progression or recurrence of these gastroduodenal diseases. ${ }^{2-4}$ However, as the antibiotic resistance of $H$. pylori has increased, the success rate of its eradication has decreased worldwide. ${ }^{5}$ In Korea and Japan, $H$. pylori resistance against clarithromy- cin has surpassed 15\%, and the eradication rate of standard triple therapy (proton pump inhibitor, amoxicillin, and clarithromycin) has decreased to an unacceptable level. ${ }^{6-10}$

According to the Maastricht V/Florence Consensus guidelines, standard triple therapy should be abandoned in regions with high resistance to clarithromycin (>15\%) without testing for the susceptibility of $H$. pylori. ${ }^{11}$ When the standard triple regimen is considered as a first-line therapy, in areas of high resistance to clarithromycin, either a culture-based susceptibility test or a molecular test (poly-

\section{Copyright $(\subset)$ Gut and Liver.}


merase chain reaction, PCR) is recommended, to detect clarithromycin resistance. ${ }^{11-15}$ Nevertheless, standard triple therapy continues to be used as a first-line therapy for $H$. pylori in Korea and Japan, without antibiotic resistance testing. ${ }^{7,16,17}$

Recently, a dual-priming oligonucleotide (DPO)-based multiplex PCR assay was made commercially available, to detect genetic mutations. ${ }^{18}$ Previous studies have demonstrated that DPO-based multiplex PCR has a sensitivity of $97.7 \%$ and a specificity of $83.1 \%$, when using culture-based susceptibility as a reference test. ${ }^{12,13}$ It correlates well with other culture-based susceptibility testing and could provide an alternative for clarithromycin resistance testing. The main mechanism of $H$. pylori resistance against clarithromycin is associated with point mutations in the domain $\mathrm{V}$ (peptidyl transferase loop) of the $23 \mathrm{~S}$ ribosomal RNA gene. $^{19}$ Among the point mutations, A2143G and A2142G are the most frequently detected, found in $64 \%$ to $95 \%$ of clarithromycin-resistant strains. ${ }^{20-23}$ Although such point mutations have been associated with different degrees of clarithromycin resistance in vitro, ${ }^{24-26}$ the clinical relevance of these mutations to $H$. pylori eradication has not yet been investigated.

The aim of this study was to detect the prevalence of the point mutations and to investigate the role of different point mutations in the success of $H$. pylori eradication therapy.

\section{MATERIALS AND METHODS}

\section{Study design and subjects}

We retrospectively reviewed a database of consecutive patients who underwent endoscopic examination and DPO-based multiplex PCR for H. pylori in St. Mary's Hospital, the Catholic University of Korea between June 2014 and October 2019. DPO-based multiplex PCR were performed for the patients who had the peptic ulcer disease, gastric cancer, low grade gastric mucosa-associated lymphoid tissue lymphoma, and history of endoscopic treatment of early-stage gastric neoplasm. We classified the patients into positive and negative point mutation groups, based on the results of DPO-based multiplex PCR test. All patients were aged over 19 and under 90 . The exclusion criteria were as follows: (1) history of gastric cancer surgery $(\mathrm{n}=1)$; (2) previous eradication therapy for $H$. pylori $(\mathrm{n}=6)$; and (3) no eradication therapy for $H$. pylori after DPO-based multiplex PCR test $(\mathrm{n}=233)$ who had severe systemic diseases or did not visit again our hospital (Fig. 1). In the negative point mutation group (absence of a $23 \mathrm{~S}$ ribosomal RNA point mutation in H. pylori), 287 patients were treated with standard triple therapy (lansoprazole 30 $\mathrm{mg}$, pantoprazole $40 \mathrm{mg}$, or rabeprazole $20 \mathrm{mg}$, clarithromycin $500 \mathrm{mg}$, and amoxicillin $1 \mathrm{~g}$, twice daily for 7 days) and two patients with a past history of penicillin allergy were treated with bismuth-quadruple therapy (lansoprazole $30 \mathrm{mg}$, pantoprazole $40 \mathrm{mg}$, or rabeprazole $20 \mathrm{mg}$ twice daily; metronidazole $500 \mathrm{mg}$ three times daily; bismuth subcitrate $300 \mathrm{mg}$ four times daily; and tetracycline 500 $\mathrm{mg}$ four times daily) for 7 or 14 days. In the positive point mutation group (A2142G and/or A2143G mutation identified by DPO-PCR), 37 patients were treated with standard triple therapy and 138 patients were treated with bismuthquadruple therapy. In the case of 37 patients with positive point mutations, non-gastrointestinal (GI) specialists who were not familiar with this test prescribed clarithromycinbased standard triple therapy despite the presence of positive point mutations. The eradication of $H$. pylori was assessed by either the rapid urease test (Halyard Health Inc., Alpharetta, GA, USA), or a standard ${ }^{13} \mathrm{C}$-urea breath test (UBiTkit, Otsuka Pharmaceutical Co. Ltd., Tokyo, Japan) at 4 to 6 weeks after completing the eradication therapy. Eradication was defined as a negative result obtained in the aforementioned tests.

\section{Point mutation test: DPO-based multiplex PCR}

Our institution has a standard protocol of endoscopic biopsy sites for $H$. pylori detection, which recommends at least two samples should be taken at the non-atrophic area. Gastric biopsy specimens were used for the DPObased multiplex PCR test. We assessed the point mutations (A2142G and A2143G) for clarithromycin resistance by using a validated Seeplex ${ }^{\circledR}$ H. pylori-ClaR ACE Detection kit (Seegene Inc., Seoul, Korea). Three primer pairs were detected, with a DPO structure consisting of a 621-base pair (bp) band, a 194-bp band and a 475-bp band, using ultraviolet transillumination, after $2 \%$ agarose gel electrophoresis. The presence of just a 621-bp band indicated that the specimen was wild-type $H$. pylori. The presence of a 194-bp band was indicative of the $\mathrm{A} 2142 \mathrm{G}$ point mutation, and a 475-bp band indicated the A2143G point mutation. The kit also included a primer pair for internal control.

\section{Outcome measures and compliance}

The eradication success rate between the negative and positive point mutation groups was evaluated by per-protocol (PP) and intention-to-treat (ITT) analyses. The PP eradication rate was expressed as a percentage of patients that completed the study. For ITT, this was expressed as a percentage of all patients who took the medicine, including those with poor compliance, or those with lack of followup. Patient-reported compliance was checked at the last 


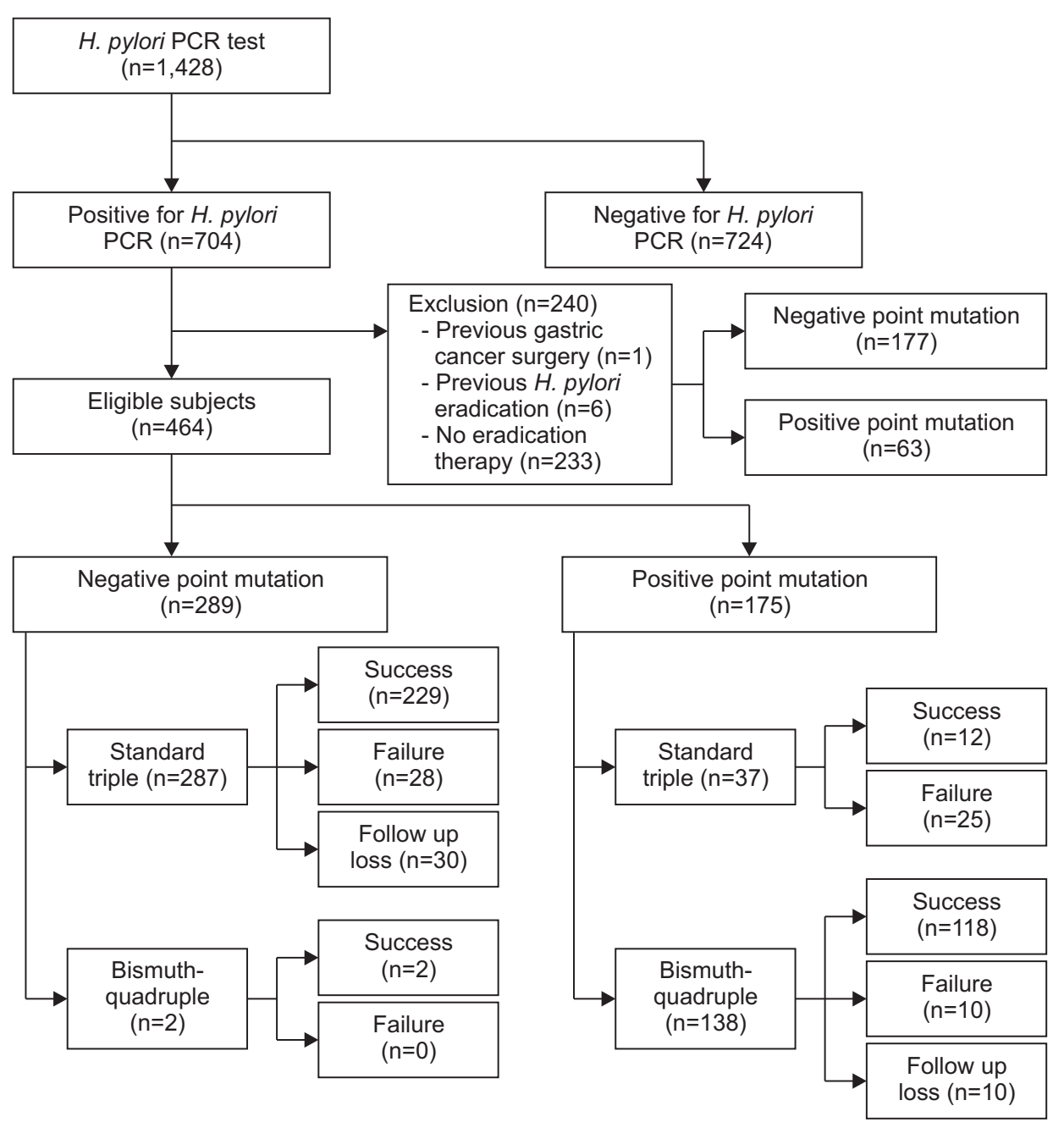

Fig. 1. Flow diagram of subject selection.

H. pylori, Helicobacter pylori; PCR, polymerase chain reaction. hospital visit. Patients with poor compliance were defined as consumption of less than $80 \%$ of the prescribed medicines, and were excluded from the PP analysis.

\section{Statistical analysis}

We determined point mutation groupings after reviewing eradication rates by individual mutation. Continuous data were expressed by using mean and standard deviation and were compared with the Student t-test. Categorical data were described by using number with percentage (\%) and were compared by using the chi-square test or Fisher exact test where appropriate. We compared eradication rates according to different point mutations by using the Fisher exact test or chi-square test, as appropriate. Multivariate logistic regression was performed by using therapeutic outcome as the dependent variable and by including the sex, age, smoking status, diabetes mellitus (DM), types of first-line therapy and types of point mutation groups as possible covariates. Results are presented as odds ratio (OR) with $95 \%$ confidence interval (CI). A value of $\mathrm{p}<0.05$ was considered statistically significant. We performed statistical analysis by using SPSS software version 26.0 for Window (IBM Corp., Armonk, NY, USA).

\section{Ethics statement}

This study was approved by the Institutional Review Board of the Seoul St. Mary's Hospital, the Catholic University of Korea, Seoul (IRB number: KC20RASI0002). The requirement for written informed consent was waived because anonymous data collected were used. This study followed the ethical principles of the Declaration of Helsinki.

\section{RESULTS}

\section{Characteristics of the ITT study population}

H. pylori PCR tests from biopsy specimens were performed in 1,428 patients. For 704 patients who were positive for $H$. pylori, the DPO-based multiplex PCR point mutation tests were performed. Overall rates for negative and positive point mutations were $66.2 \%$ (466/704) and $33.8 \%$ (238/704), respectively. Based on the exclusion cri- 
teria described above, 240 patients were excluded from this study (Fig. 1). In total, 464 patients were included, and 415 completed the course of treatment and examination. Forty patients did not complete the follow-up, and nine patients showed poor compliance. Among the 464 patients, point mutation rates were found to be: $62.3 \%(289 / 464)$ negative; $3.0 \%(14 / 464)$ A2142G; 34.1\% (158/464) A2143G; and $0.6 \%$ (3/464) double mutants (A2142G plus A2143G).

The baseline characteristics of all enrolled patients are shown in Table 1. In the negative and positive point mutation groups, the proportion of men was $59.9 \%$ and $55.4 \%$, with a mean age of $54.9 \pm 13.0$ and $56.2 \pm 14.3$, respectively. Smokers comprised $21.1 \%$ and $22.3 \%$, respectively. There was no significant difference between the negative and positive groups in terms of having DM, the reason for the H. pylori PCR test, the grade of atrophy, and types of follow-up test.

\section{Distribution of types of point mutations and first- line therapy}

There was significant difference in the type of firstline therapy used between the negative and positive point mutation groups $(\mathrm{p}<0.001)$ (Table 1$)$. We pooled the three patients with double point mutations (DPM) with the A2143G point mutation group, on the basis of a previous study, that considered the $\mathrm{A} 2143 \mathrm{G}$ point mutation as the dominant genotype. ${ }^{27}$ First-line therapy according to types of point mutation is shown in Table 2. Standard triple therapies were performed in $99.3 \%$ (287/289) of negative group, 28.6\% (4/14) of A2142G group, and 20.5\% (33/161) of A2143G/DPM groups, respectively. Bismuth-quadruple therapies were prescribed in $0.7 \%(2 / 289)$ of negative group, $71.4 \%(10 / 14)$ of A2142G group, and $79.5 \%$ (128/161) of A2143G/DPM group, respectively (Table 2).

Table 1. Baseline Characteristics of the Intention-to-Treat Study Population

\begin{tabular}{|c|c|c|c|}
\hline Characteristics & $\begin{array}{l}\text { Negative point mutation } \\
\qquad(n=289)\end{array}$ & $\begin{array}{l}\text { Positive point mutation } \\
\qquad(n=175)\end{array}$ & p-value \\
\hline Age, yr & $54.9 \pm 13.0$ & $56.2 \pm 14.3$ & 0.330 \\
\hline Sex & & & 0.348 \\
\hline Men & 173 (59.9) & $97(55.4)$ & \\
\hline Women & $116(40.1)$ & 78 (44.6) & \\
\hline Body mass index, $\mathrm{kg} / \mathrm{m}^{2}$ & $24.4 \pm 3.2$ & $23.8 \pm 3.6$ & 0.071 \\
\hline Smoking status & & & 0.765 \\
\hline Non-smoker & 228 (78.9) & $136(77.7)$ & \\
\hline Smoker & $61(21.1)$ & 39 (22.3) & \\
\hline Diabetes mellitus & & & 0.396 \\
\hline No & 263 (91.0) & $155(88.6)$ & \\
\hline Yes & $26(9.0)$ & $20(11.4)$ & \\
\hline Causes for H. pylori PCR test & & & 0.318 \\
\hline Gastric ulcer & $117(40.5)$ & $72(41.1)$ & \\
\hline Duodenal ulcer & $87(30.1)$ & $56(32.0)$ & \\
\hline Early gastric cancer & $59(20.4)$ & 39 (22.3) & \\
\hline Advanced gastric cancer & 0 & $1(0.6)$ & \\
\hline Gastric adenoma & $13(4.5)$ & $3(1.7)$ & \\
\hline MALToma & $13(4.5)$ & $4(2.3)$ & \\
\hline Grade of atrophy & & & 0.471 \\
\hline Normal \& close type 1 & $204(70.6)$ & $126(72.0)$ & \\
\hline Close type $2 \& 3$ & 54 (18.7) & $26(14.9)$ & \\
\hline Open type $1 \& 2 \& 3$ & $31(10.7)$ & $23(13.1)$ & \\
\hline Types of first-line therapy & & & $<0.001$ \\
\hline Standard triple & 287 (99.3) & $37(21.1)$ & \\
\hline Bismuth-quadruple & $2(0.7)$ & $138(78.9)$ & \\
\hline Types of follow-up test & & & 0.124 \\
\hline${ }^{13} \mathrm{C}$-urea breath test & 240 (83.0) & $148(84.6)$ & \\
\hline Rapid urease test & $19(6.6)$ & $17(9.7)$ & \\
\hline Follow-up test not performed & $30(10.4)$ & $10(5.7)$ & \\
\hline Types of point mutation & & & - \\
\hline A2142G & NA & $14(8.0)$ & \\
\hline A2143G & NA & $158(90.3)$ & \\
\hline Double (A2142G and A2143G) & NA & $3(1.7)$ & \\
\hline
\end{tabular}

Data are presented as the mean \pm SD or number $(\%)$.

H. pylori, Helicobacter pylori; PCR, polymerase chain reaction; MALToma, mucosa-associated lymphoid tissue lymphoma; NA, not available. 
Table 2. Eradication Rates after Standard Triple and Bismuth-Quadruple Therapies According to the Type of Point Mutation

\begin{tabular}{|c|c|c|c|}
\hline Types of first-line therapy & Negative point mutation & $\begin{array}{l}\text { Positive point mutation } \\
\qquad \text { A2142G }\end{array}$ & $\begin{array}{l}\text { Positive point mutation } \\
\text { A2143G or double }{ }^{*,+}\end{array}$ \\
\hline \multicolumn{4}{|l|}{ Per-protocol } \\
\hline Standard triple & 229/255 (89.8) & $4 / 4(100.0)$ & $8 / 31$ (25.8) \\
\hline Bismuth-quadruple & $2 / 2(100.0)$ & $9 / 9(100.0)$ & $105 / 114(92.1)$ \\
\hline \multicolumn{4}{|l|}{ Intention-to-treat } \\
\hline Standard triple & 229/287 (79.8) & $4 / 4(100.0)$ & $8 / 33$ (24.2) \\
\hline Bismuth-quadruple & $2 / 2(100.0)$ & $9 / 10(90.0)$ & $109 / 128$ (85.2) \\
\hline
\end{tabular}

Data are presented as number/total number (\%).

*Double, both $A 2142 \mathrm{G}$ and $\mathrm{A} 2143 \mathrm{G} ;{ }^{\dagger} \mathrm{p}<0.05$ for the per-protocol and intention-to-treat analyses between standard triple and quadruple therapies.

Table 3. Eradication Rates According to the Duration of Bismuth-Quadruple Therapy

\begin{tabular}{|c|c|c|c|}
\hline $\begin{array}{c}\text { Duration of bismuth-quadruple } \\
\text { therapy }\end{array}$ & Negative point mutation & $\begin{array}{l}\text { Positive point mutation } \\
\text { A2142G }\end{array}$ & $\begin{array}{l}\text { Positive point mutation } \\
\text { A2143G or double* }\end{array}$ \\
\hline \multicolumn{4}{|l|}{ Per-protocol } \\
\hline 7-day quadruple & $1 / 1(100.0)$ & $8 / 8(100.0)$ & $84 / 93(90.3)^{+}$ \\
\hline 14-day quadruple & $1 / 1(100.0)$ & $1 / 1(100.0)$ & $21 / 21(100.0)^{+}$ \\
\hline \multicolumn{4}{|l|}{ Intention-to-treat } \\
\hline 7-day quadruple & $1 / 1(100.0)$ & 8/9 (88.9) & $86 / 105(81.9)^{\ddagger}$ \\
\hline 14-day quadruple & $1 / 1(100.0)$ & $1 / 1(100.0)$ & $23 / 23(100.0)^{\ddagger}$ \\
\hline
\end{tabular}

Data are presented as number/total number (\%).

*Double, both A2142G and A2143G; ${ }^{\dagger}$ Two patients who received 7-day quadruple therapy had poor compliance, and two patients who received 14day quadruple had poor compliance; ${ }^{\ddagger} \mathrm{p}=0.024$ for the intention-to-treat analysis between 7 -day and 14 -day quadruple therapies.

\section{Point mutations and therapeutic outcomes}

After the standard triple and bismuth-quadruple therapy in the negative point mutation group, eradication by $\mathrm{PP}$ analysis was $89.8 \%(\mathrm{n}=229 / 255)$ and $100 \%(\mathrm{n}=2 / 2)$, respectively (difference, 10.2 percentage points; $95 \%$ CI, -75.4 to $8.2 ; \mathrm{p}>0.99)$. The eradication rates by ITT analysis were $79.8 \%(n=229 / 287)$ and $100 \%(n=2 / 2)$, respectively (difference, 20.2 percentage points; $95 \%$ CI, -65.0 to 29.2; $\mathrm{p}>0.99$ ). The eradication rate between standard triple and bismuth-quadruple therapy was not significantly different in patients with negative point mutations (Table 2).

After the standard triple and bismuth-quadruple therapy in the A2142G point mutation group, eradication rate by $\mathrm{PP}$ analysis was $100 \%(\mathrm{n}=4 / 4)$ and $100 \%(\mathrm{n}=9 / 9)$, respectively (difference, 0.0 percentage point; $95 \% \mathrm{CI}$, not available). The eradication rate by ITT analysis was $100 \%$ $(\mathrm{n}=4 / 4)$ and $90.0 \%(\mathrm{n}=9 / 10)$, respectively (difference, 10.0 percentage points; $95 \% \mathrm{CI},-47.2$ to $47.1 ; \mathrm{p}>0.99$ ). The eradication rate between standard triple and bismuth-quadruple therapy was not significantly different in patients with $\mathrm{A} 2142 \mathrm{G}$ point mutations (Table 2).

In the A2143G/DPM group, after the standard triple and bismuth-quadruple therapy, the eradication rate by $\mathrm{PP}$ analysis was $25.8 \%(\mathrm{n}=8 / 31)$ and $92.1 \%(\mathrm{n}=105 / 114)$, respectively (difference, 66.3 percentage points; 95\% CI, 50.1 to $82.5 ; \mathrm{p}<0.001)$. The eradication rates by ITT analysis were $24.2 \%(n=8 / 33)$ and $85.2 \%(n=109 / 128)$, respectively (difference, 61.0 percentage points; 95\% CI, 45.0 to 76.8 ; $\mathrm{p}<0.001)$. In both PP and ITT analyses, the eradication rate with bismuth-quadruple therapy was significantly higher than that with standard triple therapy in patients with infection by A2143G/DPM mutants (Table 2). Eradication rates after second-line therapy in patients with negative and positive point mutations are described in Supplementary Tables 1 and 2.

\section{Eradication rates according to duration of bismuth- quadruple therapy}

In the $\mathrm{A} 2142 \mathrm{G}$ mutation group, eradication rates were not significantly different between the 7-day and 14-day quadruple therapy in both PP and ITT analyses. In the A2143G/DPM group, eradication rates with 14-day quadruple therapy were significantly higher than those with 7 -day quadruple therapy in ITT analysis (100\% vs $81.9 \%$; difference, 18.1 percentage points; $95 \% \mathrm{CI},-1.3$ to 27.1 ; $\mathrm{p}=0.024$ ), but not in PP analysis ( $100 \%$ vs $90.3 \%$; difference, 9.7 percentage points; $95 \% \mathrm{CI},-8.4$ to $18.0 ; \mathrm{p}=0.206$ ) (Table 3).

\section{Clinical factors associated with H. pylori eradication failure}

To determine whether the different point mutations and types of first-line therapy are associated with failure to eradicate H. pylori, we conducted univariate and mul- 
tivariate analyses (Table 4, Supplementary Tables 3 and 4). For the risk of treatment failure, the interaction effect between the different point mutations and types of firstline therapy was significant $(\mathrm{p}=0.019)$. In addition, patients were not evenly distributed according to first-line therapy and the two-point mutations. Accordingly, separate multivariate analyses were performed for each of these variables (Table 4). On multivariate analysis, including types of firstline therapy, bismuth-quadruple therapy (OR, 0.39; 95\% CI, 0.18 to $0.82 ; \mathrm{p}=0.014)$ and $\mathrm{DM}(\mathrm{OR}, 2.17 ; 95 \% \mathrm{CI}, 1.01$ to $4.64 ; \mathrm{p}=0.047)$ were associated with $H$. pylori eradication (Supplementary Table 4). Meanwhile, on multivariate analyses, including the different point mutations, A2143G/ DPM (OR, 2.44; 95\% CI, 1.38 to 4.34; $\mathrm{p}=0.002$ ) was associated with $H$. pylori eradication failure (Table 4 ).

\section{DISCUSSION}

The prevalence of $23 \mathrm{~S}$ rRNA point mutations identified by DPO-based multiplex PCR was $37.7 \%$ in this study population. The A2143G point mutation was the most prevalent, accounting for $90.3 \%$ of cases. The remaining patients had $\mathrm{A} 2142 \mathrm{G}$ point mutations (8.0\%) or both $\mathrm{A} 2142 \mathrm{G}$ and A2143G point mutations (1.7\%). In patients with A2143G or DPM, bismuth-quadruple therapy achieved a higher eradication rate than standard triple therapy, as first-line therapy (92.1\% vs $25.8 \%$ in PP analysis, $85.2 \%$ vs $24.2 \%$ in ITT analysis). Meanwhile, patients with $\mathrm{A} 2142 \mathrm{G}$ point mutations showed high eradication rates, using both standard triple or bismuth-quadruple therapy as first-line therapy. We also found A2143G/DPM to be an independent risk

Table 4. Clinical Factors Associated with Helicobacter pylori Eradication Failure (Including the Type of Point Mutation)

\begin{tabular}{lccc}
\hline \multirow{2}{*}{ Variable } & \multicolumn{3}{c}{ Multivariate analysis } \\
\cline { 2 - 4 } & OR & $95 \% \mathrm{Cl}$ & $\mathrm{p}$-value \\
\hline Age & 1.02 & $1.00-1.04$ & 0.111 \\
Sex & & & \\
$\quad$ Men & Reference & & \\
$\quad$ Women & 0.91 & $0.47-1.76$ & 0.775 \\
Smoking status & & & \\
$\quad$ Non-smoker & Reference & & \\
Smoker & 1.69 & $0.82-3.50$ & 0.156 \\
Diabetes mellitus & & & \\
$\quad$ No & Reference & & \\
Yes & 2.09 & $0.97-4.51$ & 0.061 \\
Types of point mutation & & & \\
Negative & Reference & & \\
Positive A2142G & NA & & \\
Positive A2143G and double* & 2.44 & $1.38-4.34$ & 0.002 \\
\hline
\end{tabular}

$\mathrm{OR}$, odds ratio; $\mathrm{Cl}$, confidence interval; $\mathrm{NA}$, not available.

*Double, both A2142G and A2143G. factor for failure to eradicate, even after adjusting for sex, age, smoking, and DM.

The Maastricht V/Florence consensus has recommended the use of culture antibiotic susceptibility tests for H. pylori, in areas with high clarithromycin resistance $(>15 \%) .{ }^{11}$ However, antibiotic susceptibility tests using culture methods are time-consuming and require dedicated expertise. ${ }^{20}$ In addition, the cost-effectiveness of these tests for improved eradication rates has not been clearly identified. ${ }^{28}$ Therefore, it is difficult to perform this test routinely in clinical practice before the initiation of eradication therapy. Several international guidelines have suggested that bismuth-quadruple therapy is an option for first-line treatment. ${ }^{3,11}$ However, there are some concerns in using this as an initial therapy because it includes a complex combination of antibiotics. This therapy might increase treatmentrelated side effects and result in inappropriate antibiotic overuse. ${ }^{29,30}$ In these circumstances, a novel DPO-based multiplex PCR test was recently developed to identify $H$. pylori infection and to detect the point mutations associated with resistance to clarithromycin. ${ }^{12,13}$ This moleculebased assay could provide rapid and accurate results for identifying clarithromycin resistance in $H$. pylori. Therefore, it is considered as an alternative method to culture or antibiotic susceptibility tests, and is a realistic option for choosing the appropriate eradication regimen in a region with increasing clarithromycin resistance. ${ }^{12,13,18}$ We investigated the clinical relevance of different point mutations in the $23 \mathrm{~S}$ rRNA gene, identified by DPO-based multiple PCR.

The overall prevalence of point mutations (37.7\%) in our study was similar to that reported in a previous study from Korea, which showed that the clarithromycin resistance rate was $37.0 \%$ from 2009 to $2012 .{ }^{31}$ The prevalence of A2143G (90.3\%) and A2142G (8.0\%) point mutations is also similar to that reported in other Korean studies, ${ }^{32,33}$ but different from the prevalence found in patients from Western studies. ${ }^{27,34}$ In general, the A2143G mutation accounts for the majority of point mutations associated with clarithromycin resistance.

This study showed that patients with A2143G or DPM showed low eradication rate with standard triple therapy. A2142G point mutation seems to be not related with clarithromycin resistance. However, the cases having this mutation was too small to demonstrate this in the present study. The different therapeutic results among the different point mutations could be explained by different affinities of clarithromycin binding to the ribosome, due to diverse 3-dimensional, structural changes in the binding site. ${ }^{27,35}$ The A2143G point mutation could be considered as a high-risk genotype, with a high eradica- 
tion failure rate over standard triple therapy. Boyanova et al. $^{26}$ demonstrated the associations between A2143G point mutation and less virulent vacA i2 strains, and between $\mathrm{A} 2142 \mathrm{G}$ point mutation and more virulent vacA i1 strains. Compared with more virulent strains of $H$. pylori, less virulent strains cause less inflammation in the gastric mucosa, and this might decrease the chance of successful eradication. ${ }^{26,36}$ This previous report might help in the understanding of our results, which showed a lower eradication rate of bismuth-quadruple therapy in patients with the A2143G point mutation compared to A2142G. However, it achieved significantly higher eradication rates in patients with A2143G/DPM, compared to standard triple therapy. Based on the evidence, we propose a tailored treatment strategy for $H$. pylori infection according to the presence of the A2143G or DPM point mutation. Meanwhile, largescale studies are still needed to demonstrate whether standard triple therapy is effective in patients with the A2142G point mutation because of small number of cases. Consistent with our findings, a recent prospective observational study showed that tailored therapy based on the type of $23 \mathrm{~S}$ rRNA point mutation can improve eradication rates as well as cost-effectiveness in patients with $H$. pylori infection, compared to empiric standard triple therapy. ${ }^{37}$

Some patients were treated with standard triple therapy even in the presence of point mutations at the beginning of this study. When the DPO-based multiplex PCR was introduced in our institution, it was not familiar to non-GI specialists. Furthermore, there was not enough researches about this test. Endoscopic examinations and DPO-based multiplex PCR of these patients were performed by GI specialists, but eradication regimen against $H$. pylori was prescribed by non-GI specialists as well. After then, our institution put the meaning of these mutations in the DPObased multiplex PCR result document in order to induce appropriate practice for $H$. pylori eradication, as follows: "This test is a method to detect point mutations that were related with clarithromycin resistance by a PCR. The presence of point mutations can be used to diagnose clarithromycin resistance."

This study had several limitations. First, a DPO-based multiplex PCR test is limited to the detection of A2142G and $\mathrm{A} 2143 \mathrm{G}$ point mutations. Other point mutations, such as $\mathrm{A} 2142 \mathrm{C}$ or $\mathrm{A} 2144 \mathrm{G}$, cannot be detected, although they usually represent $<5 \%$ of resistant genotypes. Second, the number of patients with $\mathrm{A} 2142 \mathrm{G}$ point mutation was small and only four patients with the mutation were treated by standard triple therapy. Third, this study was conducted at a single tertiary center in Korea. Thus, it has been subject to selection bias, and the findings cannot be generalized. Fourth, DPO-based multiplex PCR could determine only

the presence of clarithromycin resistance, and we did not attempt $H$. pylori cultures for other antibiotic susceptibility tests. Fifth, $H$. pylori status was assessed at 4 to 6 weeks after the end of treatment by various diagnostic methods, such as the rapid urease test or a ${ }^{13} \mathrm{C}$-urea breath test. The diagnostic accuracy of these methods is $>90 \%$, according to a previous report, ${ }^{38}$ so we considered that the different diagnostic methods did not significantly affect the analysis. Sixth, heterogeneity of $H$. pylori within a single subject might result in treatment failure, even after a bismuth-quadruple therapy for the presence of a $23 \mathrm{~S}$ rRNA point mutation. ${ }^{39}$ Finally, we could not investigate how many patients underwent gastric biopsy according to the standard biopsy protocol for H. pylori.

In conclusion, this study showed that A2143G, rather than $\mathrm{A} 2142 \mathrm{G}$, was the prevalent point mutation attributed to clarithromycin resistance. For patients with A2143G or DPM, bismuth-quadruple therapy is superior to standard triple therapy as the first-line therapy. Different types of point mutation could affect the success rate of $H$. pylori eradication, but further large-scale studies are needed.

\section{CONFLICTS OF INTEREST}

No potential conflict of interest relevant to this article was reported.

\section{AUTHOR CONTRIBUTIONS}

Conceptualization: J.M.P., C.H.L., Y.K.C., M.G.C. Data curation: S.Y.K., Y.C., G.Y.S. Formal analysis: J.M.P., C.H.L., S.Y.K., H.A.L. Investigation: J.M.P., C.H.L., S.Y.K. Methodology: J.M.P., C.H.L., S.Y.K., H.A.L. Writing - original draft: S.Y.K., J.M.P., C.H.L. Writing - review \& editing: J.M.P., C.H.L., Y.K.C., M.G.C.

\section{ORCID}

Sang Yoon Kim Jae Myung Park Chul-Hyun Lim Hye Ah Lee Ga-Yeong Shin Younghee Choe Yu Kyung Cho Myung-Gyu Choi https://orcid.org/0000-0003-4083-5187

https://orcid.org/0000-0002-1155-1495 https://orcid.org/0000-0002-1534-7467 https://orcid.org/0000-0002-8347-8979 https://orcid.org/0000-0002-4051-0350 https://orcid.org/0000-0001-7485-2212 https://orcid.org/0000-0002-9443-2108 https://orcid.org/0000-0002-7297-6577 


\section{REFERENCES}

1. Fallone CA, Moss SF, Malfertheiner P. Helicobacter pylori Infection. N Engl J Med 2019;381:588.

2. Sugano K, Tack J, Kuipers EJ, et al. Kyoto global consensus report on Helicobacter pylori gastritis. Gut 2015;64:13531367.

3. Fallone CA, Chiba N, van Zanten SV, et al. The Toronto consensus for the treatment of Helicobacter pylori infection in adults. Gastroenterology 2016;151:51-69.

4. Chey WD, Leontiadis GI, Howden CW, Moss SF. ACG clinical guideline: treatment of Helicobacter pylori infection. Am J Gastroenterol 2017;112:212-239.

5. Thung I, Aramin H, Vavinskaya V, et al. Review article: the global emergence of Helicobacter pylori antibiotic resistance. Aliment Pharmacol Ther 2016;43:514-533.

6. Graham DY, Fischbach L. Helicobacter pylori treatment in the era of increasing antibiotic resistance. Gut 2010;59:11431153.

7. Kim SG, Jung HK, Lee HL, et al. Guidelines for the diagnosis and treatment of Helicobacter pylori infection in Korea, 2013 revised edition. J Gastroenterol Hepatol 2014;29:13711386.

8. Kim SE, Park MI, Park SJ, et al. Trends in Helicobacter pylori eradication rates by first-line triple therapy and related factors in eradication therapy. Korean J Intern Med 2015;30:801-807.

9. Kim BJ, Kim HS, Song HJ, et al. Online registry for nationwide database of current trend of Helicobacter pylori eradication in Korea: interim analysis. J Korean Med Sci 2016;31:1246-1253.

10. Kato M, Ota H, Okuda M, et al. Guidelines for the management of Helicobacter pylori infection in Japan: 2016 Revised Edition. Helicobacter 2019;24:e12597.

11. Malfertheiner P, Megraud F, O'Morain CA, et al. Management of Helicobacter pylori infection-the Maastricht V/Florence Consensus Report. Gut 2017;66:6-30.

12. Woo HY, Park DI, Park H, et al. Dual-priming oligonucleotide-based multiplex PCR for the detection of Helicobacter pylori and determination of clarithromycin resistance with gastric biopsy specimens. Helicobacter 2009;14:22-28.

13. Lehours P, Siffré E, Mégraud F. DPO multiplex PCR as an alternative to culture and susceptibility testing to detect $\mathrm{He}$ licobacter pylori and its resistance to clarithromycin. BMC Gastroenterol 2011;11:112.

14. Smith SM, O'Morain C, McNamara D. Antimicrobial susceptibility testing for Helicobacter pylori in times of increasing antibiotic resistance. World J Gastroenterol 2014;20:9912-9921.

15. Pohl D, Keller PM, Bordier V, Wagner K. Review of current diagnostic methods and advances in Helicobacter pylori diagnostics in the era of next generation sequencing. World J Gastroenterol 2019;25:4629-4660.

16. Yoon KH, Park SW, Lee SW, Kim BJ, Kim JG. Clarithromycin-based standard triple therapy can still be effective for Helicobacter pylori eradication in some parts of the Korea. J Korean Med Sci 2014;29:1240-1246.

17. Yamade M, Sugimoto M, Uotani T, Nishino M, Kodaira C, Furuta T. Resistance of Helicobacter pylori to quinolones and clarithromycin assessed by genetic testing in Japan. J Gastroenterol Hepatol 2011;26:1457-1461.

18. Chung WC, Jung SH, Oh JH, et al. Dual-priming oligonucleotide-based multiplex PCR using tissue samples in rapid urease test in the detection of Helicobacter pylori infection. World J Gastroenterol 2014;20:6547-6553.

19. Agudo S, Pérez-Pérez G, Alarcón T, López-Brea M. Rapid detection of clarithromycin resistant Helicobacter pylori strains in Spanish patients by polymerase chain reactionrestriction fragment length polymorphism. Rev Esp Quimioter 2011;24:32-36.

20. Mégraud F, Lehours P. Helicobacter pylori detection and antimicrobial susceptibility testing. Clin Microbiol Rev 2007;20:280-322.

21. Cambau E, Allerheiligen V, Coulon C, et al. Evaluation of a new test, genotype HelicoDR, for molecular detection of antibiotic resistance in Helicobacter pylori. J Clin Microbiol 2009;47:3600-3607.

22. Gerrits MM, van Vliet AH, Kuipers EJ, Kusters JG. Helicobacter pylori and antimicrobial resistance: molecular mechanisms and clinical implications. Lancet Infect Dis 2006;6:699-709.

23. Francavilla R, Lionetti E, Castellaneta S, et al. Clarithromycin-resistant genotypes and eradication of Helicobacter pylori. J Pediatr 2010;157:228-232.

24. Versalovic J, Shortridge D, Kibler K, et al. Mutations in $23 \mathrm{~S}$ rRNA are associated with clarithromycin resistance in Helicobacter pylori. Antimicrob Agents Chemother 1996;40:477480 .

25. Mégraud F. H pylori antibiotic resistance: prevalence, importance, and advances in testing. Gut 2004;53:1374-1384.

26. Boyanova L, Markovska R, Yordanov D, Gergova G, Mitov I. Clarithromycin resistance mutations in Helicobacter pylori in association with virulence factors and antibiotic susceptibility of the strains. Microb Drug Resist 2016;22:227-232.

27. De Francesco V, Margiotta M, Zullo A, et al. Clarithromycinresistant genotypes and eradication of Helicobacter pylori. Ann Intern Med 2006;144:94-100.

28. Park CS, Lee SM, Park CH, et al. Pretreatment antimicrobial susceptibility-guided vs. clarithromycin-based triple therapy for Helicobacter pylori eradication in a region with high rates of multiple drug resistance. Am J Gastroenterol 2014;109:1595-1602. 
29. Choi YI, Chung JW, Park DK, et al. Tailored eradication vs empirical bismuth-containing quadruple therapy for firstline Helicobacter pylori eradication: a comparative, open trial. World J Gastroenterol 2019;25:6743-6751.

30. Ko SW, Kim YJ, Chung WC, Lee SJ. Bismuth supplements as the first-line regimen for Helicobacter pylori eradication therapy: systemic review and meta-analysis. Helicobacter 2019;24:e12565.

31. Lee JW, Kim N, Kim JM, et al. Prevalence of primary and secondary antimicrobial resistance of Helicobacter pylori in Korea from 2003 through 2012. Helicobacter 2013;18:206214.

32. Chang YW, Ko WJ, Oh CH, et al. Clarithromycin resistance and female gender affect Helicobacter pylori eradication failure in chronic gastritis. Korean J Intern Med 2019;34:10221029.

33. Lee HJ, Kim JI, Cheung DY, et al. Eradication of Helicobacter pylori according to $23 \mathrm{~S}$ ribosomal RNA point mutations associated with clarithromycin resistance. J Infect Dis 2013;208:1123-1130.
34. Owen RJ. Molecular testing for antibiotic resistance in Helicobacter pylori. Gut 2002;50:285-289.

35. Stone GG, Shortridge D, Versalovic J, et al. A PCR-oligonucleotide ligation assay to determine the prevalence of $23 \mathrm{~S}$ rRNA gene mutations in clarithromycin-resistant Helicobacter pylori. Antimicrob Agents Chemother 1997;41:712714.

36. Šterbenc A, Jarc E, Poljak M, Homan M. Helicobacter pylori virulence genes. World J Gastroenterol 2019;25:4870-4884.

37. Cho JH, Jeon SR, Kim HG, Jin SY, Park S. Cost-effectiveness of a tailored Helicobacter pylori eradication strategy based on the presence of a $23 \mathrm{~S}$ ribosomal RNA point mutation that causes clarithromycin resistance in Korean patients. J Gastroenterol Hepatol 2019;34:700-706.

38. Bilal R, Khaar B, Qureshi TZ, et al. Accuracy of noninvasive 13C-urea breath test compared to invasive tests for Helicobacter pylori detection. J Coll Physicians Surg Pak 2007;17:84-88.

39. Blaser MJ. Heterogeneity of Helicobacter pylori. Eur J Gastroenterol Hepatol 2012;9 Suppl 1:S3-S6. 